\title{
Past and Present Ecohydrology of the Peace-Athabasca Delta, Northern Alberta, Canada: Water Isotope Tracers Lead the Way
}

\author{
Brent B. Wolfe ${ }^{1}$, Thomas W.D. Edwards ${ }^{1}$ and Roland I. Hall ${ }^{2}$ \\ PAD research group, Departments of Earth Sciences ${ }^{1}$ and Biology ${ }^{2}$, University of Waterloo, Waterloo ON, Canada \\ bwolfe@uwaterloo.ca; twdedwar@uwaterloo.ca; rihall@uwaterloo.ca
}

The Peace-Athabasca Delta (PAD), situated at the confluence of the Peace and Athabasca Rivers at the western end of Lake Athabasca, is one of the world's largest freshwater deltas, containing a myriad of shallow lakes and wetlands, which support bountiful wildlife, including migratory waterfowl and a large population of North American bison. Although lying at boreal latitudes, the PAD constitutes a unique extra-limital prairie wetland complex ecologically, as well as being a key node in the Mackenzie River drainage system, the single largest source of freshwater discharge to the Arctic Ocean from continental North America. The PAD also has important indigenous and historical cultural significance and is recognized internationally as a UNESCO World Heritage Site.

Extensive multidisciplinary research efforts are being conducted to gain better understanding of the present and past ecohydrology of the PAD, with the aim of assessing the impact of both natural and anthropogenic factors, ranging from climatic variability and change to the influence of river flow regulation resulting from hydroelectric power generation at the headwaters of the Peace River (Prowse and Lalonde, 1996; Timoney et al., 1997; Cohen, 1997). The latter is of particular interest because of the possibility that alteration of the discharge characteristics of the Peace River may be affecting the frequency and magnitude of spring ice-jam flooding, which plays an important role in the water balance of many lakes and wetlands that are perched above the level of other, more frequent, highwater events (e.g., see Prowse and Conly, 1998, 2000). This is an important consideration for effective longterm environmental stewardship of the PAD in the face of future climatic variability and change, as well as the likelihood of increasing demand for

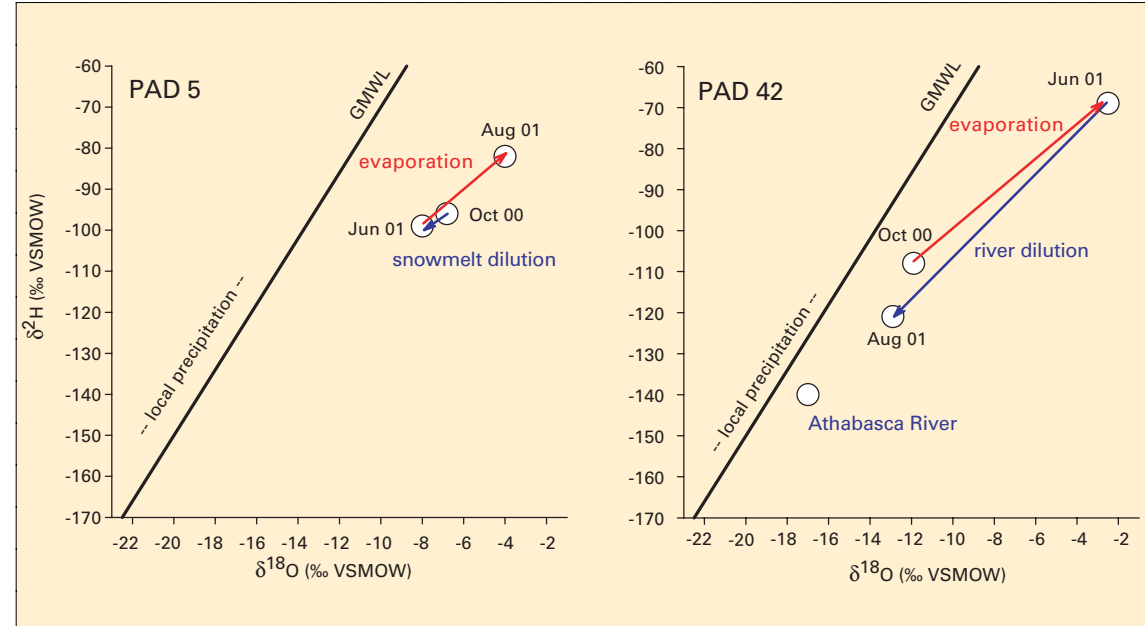

Fig. 1: $\delta^{18} \mathrm{O}-\delta^{2} \mathrm{H}$ plots showing temporal variations in the isotopic composition of two PAD lakes sampled on three occasions, at ice-on in October 2000, and relatively early and late in the open-water season in June and August 2001. As noted in the text, although similar in morphology and exposed to identical meteorological conditions, the two water bodies exhibit strikingly different isotopic evolutions. Such highly lake-specific effects need to be carefully considered in the interpretation of stratigraphic records of water isotopes, as well as other biological, physical and geochemical tracers

hydroelectric power and consumptive water use.

Our studies of the modern ecohydrology are spearheaded by utilization of the water isotope tracers ${ }^{18} \mathrm{O}$ and ${ }^{2} \mathrm{H}$ to assess instantaneous water balance in selected lakes and especially to detect events such as high-water flooding, which is difficult to monitor directly because of the remote setting and extremely subdued topography of the PAD. Information about the present hydrologic status and variability of lakes is crucial to the interpretation and calibration of other biological, physical and geochemical indicators (e.g., diatoms, plant macrofossils, pigments, $\mathrm{C}$ and $\mathrm{N}$ elemental and isotopic composition of organic matter, sediment granulometry and geochemistry), which are being used in company with oxygen isotope data from aquatic cellulose to reconstruct the history of selected PAD lakes from sediment cores.

An impression of the dynamic and individualistic behaviour of lakes in the PAD can be gained from the $\delta^{18} \mathrm{O}-\delta^{2} \mathrm{H}$ crossplots for sequential sampling of lakes PAD 5 and PAD 42 shown in Figure 1. PAD 5, a shallow $(\sim 1 \mathrm{~m})$ perched lake in a forested part of the Peace sector that normally receives river water only in the event of major ice-jam floods, reveals significant changes in isotopic composition between sampling episodes in October 2000, June 2001 and August 2001. Slight depletion in heavy-isotope content between October 2000 and June 2001, attributable to dilution by local precipitation (mostly snowmelt), was followed by progressive evaporative enrichment over the summer captured by the sample obtained in August 2001. PAD 42, a lake of comparable size and depth in a sparsely forested area in the Athabasca sector having frequent river connection, on the other hand, behaved in a strongly contrasting manner, marked by pronounced heavy-isotope enrichment between October 2000 and June 2001 due to the overwhelming influence of evaporation on the water balance of the lake after ice-off in the spring, in spite of contributions from snowmelt runoff. This was followed by a profound shift to lower values by August 2001, obscuring the effects of seasonal evaporation, deriving from a mid-summer high-water event in 


\title{
Science Highlights
}

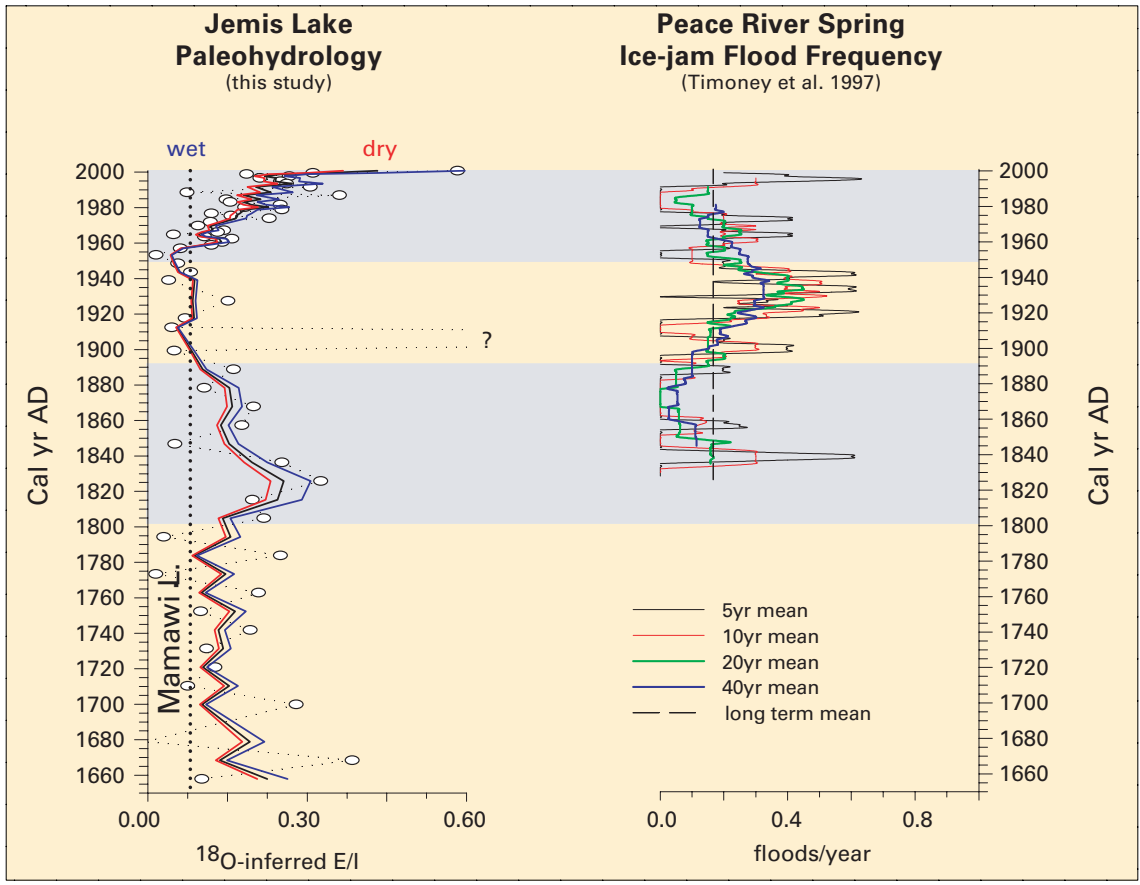

Fig. 2: Comparison of isotope-inferred water balance lexpressed as evaporation/inflow ratio, E/I) of Jemis Lake with Peace River ice-jam flood frequency reconstructed from observational and anecdotal evidence by Timoney et al. (1997). Two multi-decadal periods of relatively dry conditions (high average E/l, marked by shaded zones) in Jemis Lake and persistently low icejam flood frequency have apparently occurred within the past 175 years, with the current dry phase beginning in the mid-1900s. [Note: This first-order estimation of paleo E/I ratios for Jemis Lake is based on variations in measured $\delta^{18} \mathrm{O}$ of aquatic cellulose, assuming "Craig-type" evaporative enrichment of lake waters fed by source waters of constant isotopic composition (e.g., see Gibson, 2001, Wolfe et al., 2001a, b). The modelled values are smoothed by a threepoint running mean, and assume an ice-free season relative humidity of $55 \pm 10 \%$ (black line bracketed by red and blue). The modern E/l ratio for nearby Mamawi Lake (vertical dashed line) provides a reasonable lower limit, since non-flood intervals should be marked by disconnection from this river-fed lake.]

the Athabasca River that recharged the lake with isotopically-depleted river water.

Insight gained from such observations is key to the task of reconstructing the paleohydrology of the PAD over various time periods, which is necessary to provide the context for assessing ongoing change and evolution of the system. Preliminary results from stratigraphic analysis of a short sediment core from Jemis Lake, for example, suggests that changing water balance in this lake, as inferred from aquatic cellulose $\delta^{18} \mathrm{O}$, may provide a rough proxy for ice-jam flood frequency on the Peace River, which appears to have fluctuated widely over the past several centuries (Fig. 2). Fuller integration of other multiproxy evidence is certain to refine and sharpen this isotopic tool appreciably (e.g., see Wolfe et al., 2002), as we delve deeper into the paleo-history of the PAD, as well as in extended studies planned over the coming years in the Slave and Mackenzie deltas, downstream.

\section{ACKNOWLEDGEMENTS}

We wish to thank the British Columbia Hydro and Power Authority, the Natural Sciences and Engineering Research Council of Canada, the staff of Wood Buffalo National Park, and Indian and Northern Affairs Canada for support of this research, and especially for the training opportunities it affords our students.

\section{REFERENCES}

Cohen, S.J., 1997: What if and so what in northwest Canada: Could climate change make a difference to the future of the Mackenzie Basin? Arctic 50: 293-307.

Gibson, J.J., 2001: Forest-tundra water balance signals traced by isotopic enrichment in lakes. Journal of Hydrology 251: 1-13

Prowse, T.D. and Lalonde, V., 1996: Open-water and ice-jam flooding of a northern delta. Nordic Hydrology 27: 85-100.

Prowse, T.D. and Conly, F.M., 1998: Impacts of climatic variability and flow regulation on ice-jam flooding of a northern delta. Hydrological Processes 12. $1589-1610$

For full references please consult:

www.pages-igbp.org/products/newsletters/ref2002_2.htm

\section{Lacustrine 0xygen Isotopic Records from Temperate Marl Lakes}

\author{
Richard T. Jones ${ }^{1}$ and Jim D. Marshall 2 \\ "Hawes Water Research Group" Departments of Geography' and Earth Sciences" , University of Liverpool, Liverpool, L69 3BX, UK., \\ rtjones@liv.ac.uk, isotopes@liv.ac.uk
}

Sediments from small, temperate, carbonate lakes can provide excellent archives for Late Glacial and Holocene paleo-environmental investigations. The rapid reaction of the local hydrological system to environmental change, coupled with relatively high sediment accumulation rates, facilitate high-resolution stratigraphic studies that can employ a wide range of lithological, chemical and biological proxies. Stable isotopic data can be collected relatively easily from authigenic carbonates, which precipitate in the water column, and from the calcareous skeletons of macro and micro-fossils. Ostracods that inhabit different lacustrine settings and which calcify at different times of the year potentially enable seasonal and depth variations to be determined. Carbonate oxygen isotopic data is particularly useful in that it can provide a record that can be linked to changes in temperature and meteoric precipitation on a scale that can be directly correlated with ice-core records. Because water residence times are short these isotopic records also can be used as a proxy for 'instantaneous' climate forcing - enabling the identification of lag effects and non-linear changes in other proxies which are controlled by processes acting within the lake catchment.

Sediments from several small hard-water lakes are the focus of current investigations funded by the Natural Environment Research Council. The sediment records are being calibrated by the investigation of carbonate precipitation and isotopic variation in the modern lakes (Fig. 1) and a multiproxy investigation in- 